\title{
The Curability of Leprosy.
}

F. G. Rose.

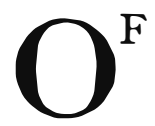

$F$ late leprologists have been showing some pessimism as to the results of the treatment of leprosy with hydnocarpus oil and its derivatives. This pessimism seems to be due to the high percentage of relapses which have occurred, and has so far penetrated to the laity as sometimes to hinder the undertaking of prophylactic measures so far as they happen to be based on the curability of the disease. It is important that this atmosphere of doubt should be cleared as far as possible, and this paper has been written with that object in view.

The sparseness of the population (some 3I0,000 souls), the accessibility of the inhabited parts of the Colony, the spectacular results of treatment, especially in cutaneous cases, are some of the factors which have enabled us to keep in touch with the great majority of patients. Of 801 patients who have come under observation, I38 are dead, I6 have left the Colony, all but one being East Indian immigrants repatriated by the Government, and of the remaining 647 , there are but 36 whose ultimate fate is not definitely known. The figures given here for relapse may therefore be taken as closely approaching complete accuracy. The "follow-up" is now done by means of out-patient clinics, of which there are six in different parts of the Colony. Here discharged patients are required to attend for periodical examination and treatment.

Originally treatment was not continued after discharge, but patients were required to visit the District Government Medical Officers at quarterly intervals for observation. It was not until I 929 that it became apparent that the percentage of relapses was so high as to cause grave doubts as to the permanence of the results achieved. It became necessary to ascertain to what cause these relapses were due. They occurred irrespective of the particular derivative of hydnocarpus oil used, the age of the patient, or the stage of the disease. Nor was it the return to unsuitable homeconditions and insufficient nutrition, for relapses occurred even in those who remained in the hospital and in some who lived in quite favourable conditions outside. We were driven to attribute their frequency to insufficient treatment.

Faced with the alternatives of retaining patients in hospital long after they had become negative, or of treating them for extended periods outside, for obvious reasons we adopted the latter. From I929 we ceased to discharge 
patients unconditionally. They are all now discharged on parole and are required to report at one of the out-patient clinics not only for examination, but also for continued treatment at monthly intervals. The results seem to bear out the correctness of our conclusions. If treatment is continued for many years-exactly how many has yet to be accurately ascertained-the relapse-rate is very far from excessive, as the accompanying tables will show.

Before proceeding, it seems desirable to make a few remarks on terminology. That recommended by the International Conference at Manila, which we follow, presents certain difficulties, to one of the most important of which attention must be drawn.

A case which has been "quiescent" for two consecutive years is termed "arrested." Thus, "arrested" cases will include not only neural cases with paralyses or loss of digits or limbs, but also cases in which function has been completely restored, the patient retaining no clinical evidence whatever of the disease. But the latter class of case is now in the majority in British Guiana, and reports wherein these are not separately tabulated may be very misleading to those not familiar with the real conditions.

It is therefore suggested that "arrested" and "quiescent" cases, that is to say, with complete restoration of function and elimination of all external evidence of the disease, should be termed "arrested and recovered" or "quiescent and recovered," as the case may be. Such expressions have been adopted for the purposes of this paper. The term "relapse" has been used in the accepted sense, and no reference is made to "interruptions" in quiescent cases.

Of the 647 known cases, I80 are cases which have been spontaneously arrested with deformity and have not received treatment during the last eight years. Thus, 467 have been under active treatment within this period, and of this number 38I have been under treatment long enough to receive Ioo c.c. or more of oil or esters.

The fate of these $38 \mathrm{I}$ patients will now be considered. 257 were classed as "early" (CI, $\mathrm{CINI}_{2}, \mathrm{C}_{2}, \mathrm{~N}_{1}$, and N2); $\mathrm{I}_{24}$ as "advanced" (C2NI, C2N2, $\mathrm{C}_{3}, \mathrm{C}_{3} \mathrm{NI}_{1}, \mathrm{C}_{3} \mathrm{~N}_{2}, \mathrm{~N}_{2} \mathrm{CI}$, $\mathrm{N}_{3}, \mathrm{~N}_{3} \mathrm{Cr}, \mathrm{N}_{3} \mathrm{C}_{2}$, and Secondary Neural).

TABLE 1. (Results in early cases).

Arrested and recovered $\quad \ldots \quad \ldots \quad \ldots$

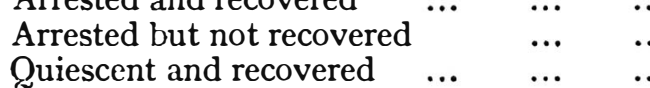

... $\quad \cdots \quad \mathbf{5 0}$

Quiescent but not recovered

$\begin{array}{lllllll}\text { Improved } \quad \ldots & \ldots & \ldots & \ldots & \ldots & 66\end{array}$

$\begin{array}{lll}\ldots & \ldots & 16\end{array}$

Worse or unchanged $\begin{array}{lllll}\cdots & \ldots & \ldots & \ldots & 49\end{array}$

Total 
That is to say, of 257 early cases, 49 show no change or are worse, while all the rest have improved, roo having become quiescent or arrested with complete restoration of function, while 66 show definite improvement, the majority with complete recovery of function, without having yet reached the stage of quiescence.

TABLE 2. (Results in advanced cases).

$\begin{array}{lllll}\text { Arrested and recovered } & \ldots & \ldots & \ldots & 6\end{array}$

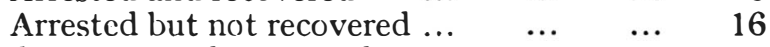

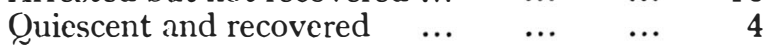

Quiescent but not recovered $\quad \ldots . \quad \ldots . \quad 11$

$\begin{array}{lllllll}\text { Improved } \quad \ldots & \ldots & \ldots & \ldots & \ldots & 66\end{array}$

$\begin{array}{lllll}\text { Worse or unchanged } & \ldots & \ldots & \ldots & 21\end{array}$

$\begin{array}{lllllll}\text { Total } & \ldots & \ldots & \ldots & & & \end{array}$

Thus, even advanced cases have a chance of recovery, though naturally much more slender than is the case in the early. They frequently require many years of treatment before showing definite signs of improvement. In our experience, in fact, hardly any advanced case of purely cutaneous nature is without hope of ultimate recovery.

It will appear from the tables given above that 98 arrested cases are now living; I3 of these, however, have eluded observation, leaving 85 whose fate is accurately known.

The following table shows the periods during which these patients have been under observation since discharge :-

Date of

Discharge.

1926-28

1929

1930

1931
Period of

Observation.

Between 5 and 7 years

4 to 5 years

3 to 4 years

2 to 3 years
No.

Arrested. Relapsed. Per ceat.

$13 \quad 2215.4$

$8 \quad 3 \quad 37.5$

$18 \quad 11 \quad 61.1$

$\begin{array}{lll}46 & 8 & 17.4\end{array}$

$$
\begin{array}{llllllll}
\text { Total } & \ldots & \ldots & \ldots & \ldots & 85 & 24 & \mathbf{2 8 . 2}
\end{array}
$$

Of the 24 relapsed cases, however, 12 have since recovered and are now again in the stage of arrest, so that up to date the number of relapsed cases is 12 out of 85 , a percentage of I4.I, which cannot be regarded as excessive.

Most of these cases have received large quantities of oil or esters or both, from Ioo to I,200 c.c.

$\begin{array}{clrcc}\text { Oil or Esters, c.c. } & & \text { No. } & \text { Relapsed. } & \text { Per cent. } \\ 100 \text { to } 200 & \ldots & 8 & 3 & 37.5 \\ 200 \text { to } 400 & \ldots & 24 & 14 & 58.3 \\ 400 \text { to } 800 & \ldots & 46 & 5 & 10.9 \\ 800 \text { to } 1,200 & \ldots & 6 & 2 & 33.3\end{array}$

Cases tend to relapse early, within the first two years after arrest. 


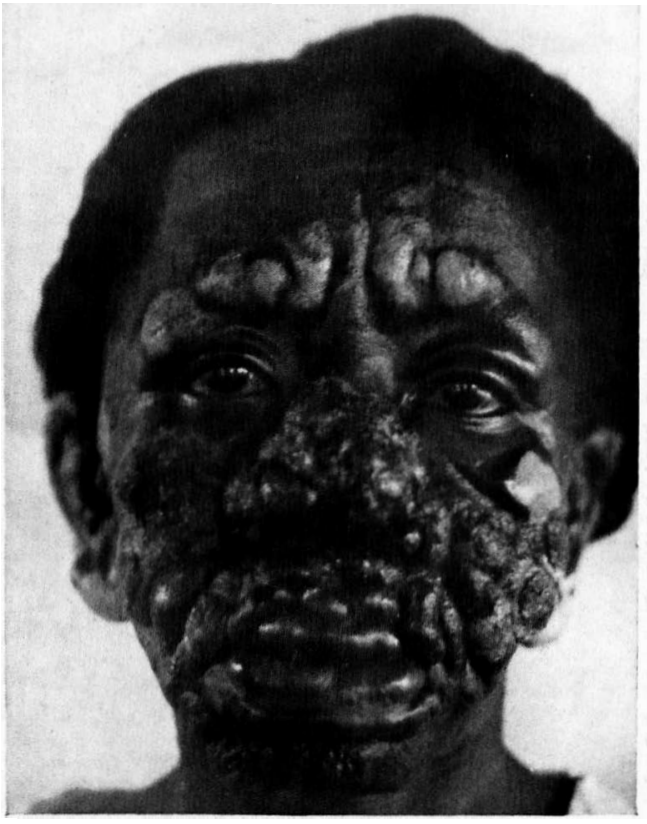

C.3 Case. On Admission

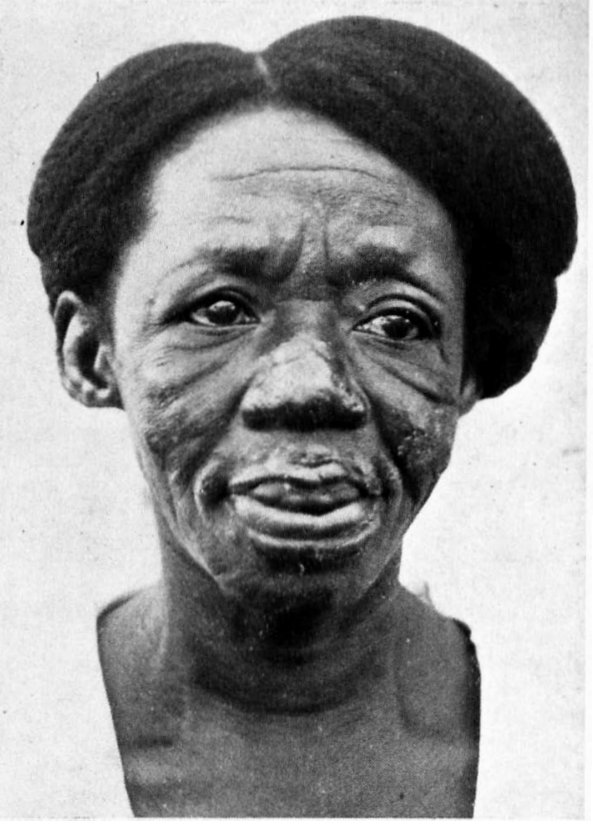

Same Case after 12 months

\section{THE CURABILITY OF LEPROSY}

No. 2

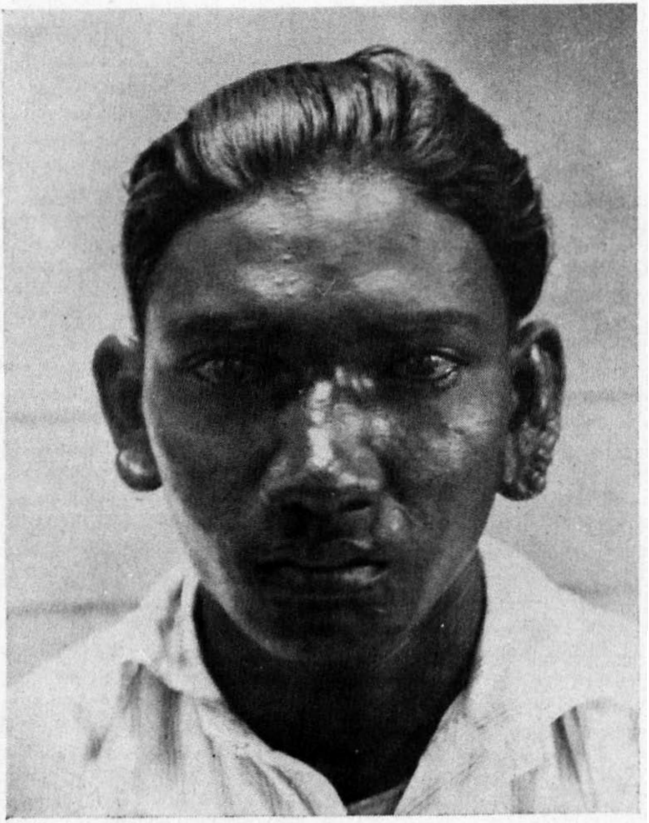

$\mathrm{C}_{3} \mathrm{~N}_{1}$ Case. On Admission
No. 2

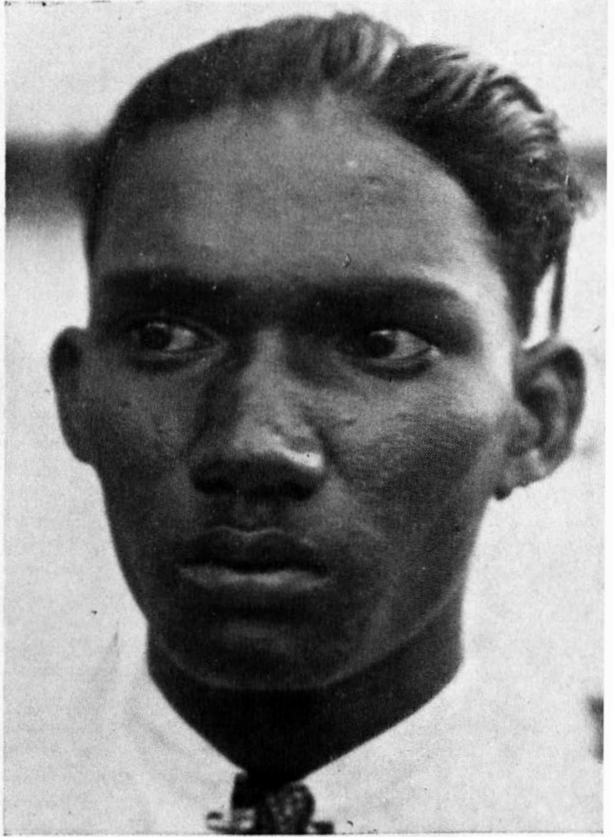

After 12 Months. Ears Trimmed by Muirs Method 
No. 3

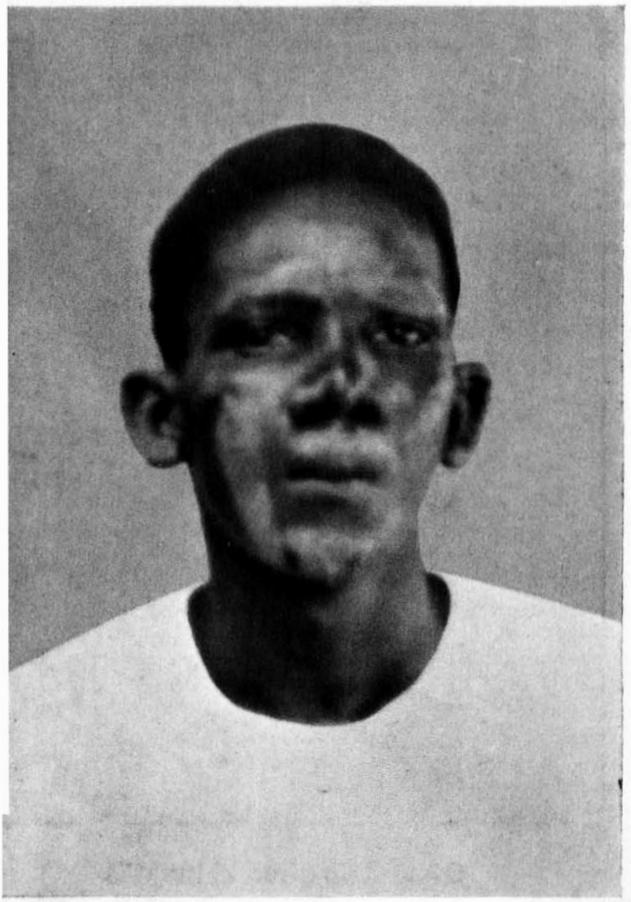

C.3. Fr Case. Soon After Admission io. 3

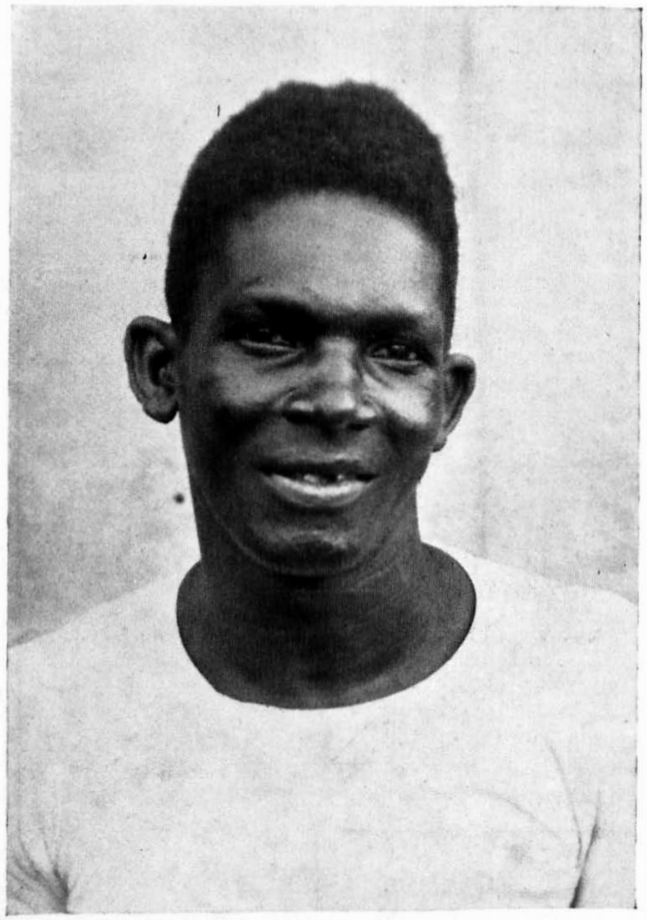

Ifter ls Months

\section{THE CURABILITY OF LEPROSY}

No: 4

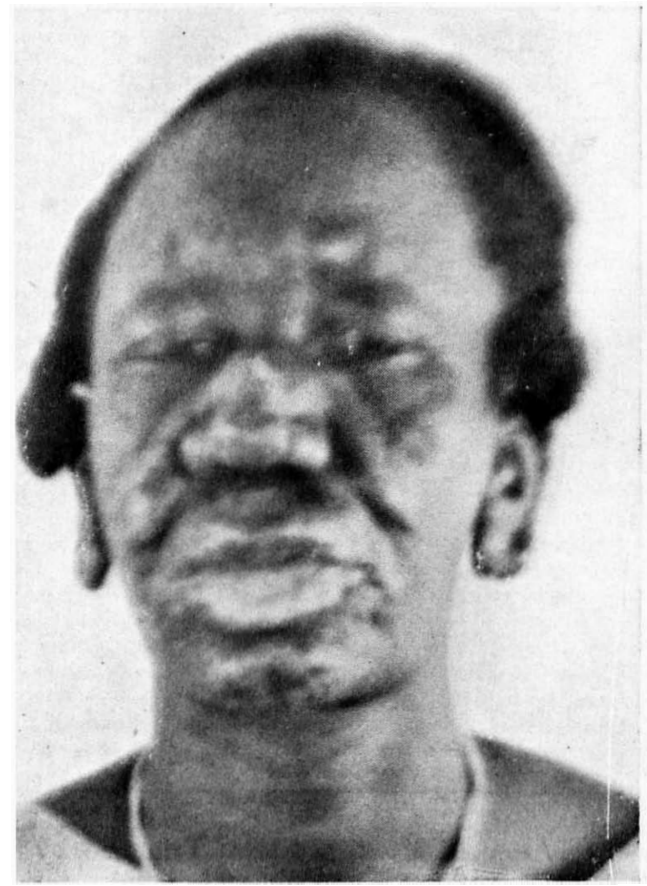

C.3 (ase. On Admission
No. 4

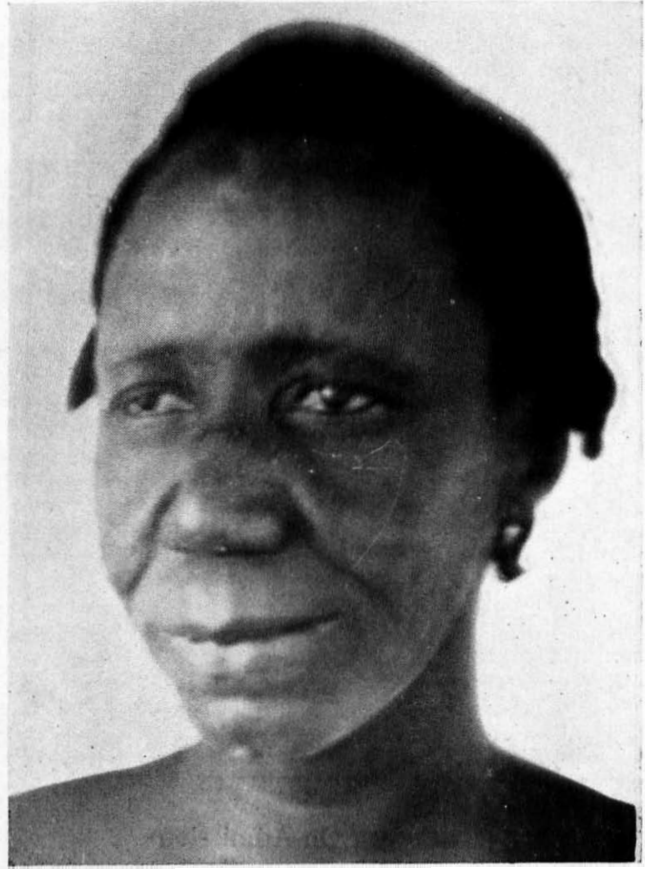

After 2 Vears 
Of the cases recorded above, 8 relapsed within $I$ year, II between I and 2 years, 3 between 2 and 3 years, and 2 between 3 and 4 years of arrest. No case has relapsed after six consecutive years of inactivity, that is to say, after remaining arrested for four consecutive years, but the number under observation for such a period is at present so limited that it would be unsafe to draw any deductions from this fact. It seems, however, that the longer the period of inactivity, the less liability there is to relapse, and there is, moreover, another group of patients, the study of whom may help to a conclusion.

Earlier in this paper, mention was made of I8o patients who had become spontaneously arrested and had been under the writer's close observation for over eight years ; indeed, some have been under his intermittent observation for some I 8 years. It is true that nearly all are cases of the neural type, not more than four being mixed (in previous years, without treatment, the average duration of life of a cutaneous case was computed at only eight years). It is also true that in two similar cases examined post-mortem after some 15 to 20 years of alleged inactivity, M. Leprae were found in profusion in dissected nerves. Nevertheless such cases would not appear to be a menace to the public health, as far as our knowledge goes at present. Of these I8o cases, three have relapsed during the last eight years, but none after five consecutive years of inactivity.

Our policy in British Guiana, based on these facts, is therefore as follows :-Treatment is continued for six years after arrest, but at longer intervals after the first three years. Patients are discharged on parole after they have reached quiescence. During this stage and up to the end of three years after arrest, treatment is given at monthly intervals. During the next three years treatment at quarterly intervals appears to suffice, though we still insist on monthly examinations. We find that patients on the whole do not regard such lengthy periods of treatment as unduly exacting, and the regularity of their attendance leaves little to be desired. When a case has remained in the arrested stage for at least six consecutive years, it may safely be deemed "cured."

One more point remains to be considered. An examination of the histories, very carefully compiled, of some I,000 patients admitted at Mahaica during several years past, shows that the large majority of infections are contracted in childhood. Cases treated in early childhood, moreover, yield more readily to treatment than the adult. 
Latterly, therefore, our efforts in British Guiana have been directed more particularly towards discovering and treating cliildhood infections.

With the aid of the British Empire Leprosy Relief Association, we have established Out-patient Clinics, at which contacts are examined and uninfectious early cases treated, and we have now I02 children under active treatment, most of them either recovered or in a fair way to recovery. We have a special building for them within the leprosy hospital, erected by private subscription, and another is in prospect for children removed from leprous parents and orphan children in the arrested stage. When this has been completed, we shall have as effective a protection from leprosy as exists in any other country in which leprosy is indigenous.

SUMMARY.

1. Of $\mathbf{8 0 1}$ patients suffering from leprosy under observation in British Guiana from 1926 to 1934,138 have died, and 16 have left the country.

2. Of the remaining 647,180 are cases spontaneously arrested, leaving 467 who have undergone active treatment during this period.

3. Fighty-six of these received treatment for less than a year, leaving 381 whose ultimate fate is considered.

4. Two hundred and fifty-seven were early cases, of whom $\mathbf{7 6}$ are now arrcsted, 66 quiescent, and 66 improved.

5. One hundred and twenty-four were advanced cases, of whom 22 are arrested, 15 quiescent, and 66 improved.

6. It is suggested that arrested and quiescent cases in whom function bas been completely restored should be termed recovered in addition.

7. Of the 142 early quiescent and arrested cases, 100, and of the 37 advanced cases 10 have completely recovered. tion.

8. Ninety-eight cases have become arrested, of whom 13 have eluded observa-

9. Of these $85,14.1 \%$ have relapsed and have not yet become re-arrestexl.

10. Relapse generally occurs within the first two years after the arrested stage has been reached.

11. Treatment should be continued for at least six years after arrest.

12. An arrested case may be deemed cured after six consecutive ycers of inactivity.

13. Special attention should be devoted to childhood infection.

We have received the following comments on Dr. Rose's article :

From Dr. J. M. H. MACLEOD, one of the leading dermatologists in this country:-

I was very glad to have your reprint of Rose's paper, but have some diffidence in appearing as a critic of it owing to my experience being so much confined to cases in this country. It seems to me, however, that this is a very fair paper, and so guarded and careful as to be more convincing than a good many I have read on the same subject.

I am not convinced, however, that it makes good the claim for specificity of hydnocarpus oil and its derivaties. It rather takes me back to the time when there was a very strong boom in cod liver oil in the treatment of tuberculosis. We are all familiar with cases of tubercle 
which after a period of years have become quiescent and to all intents and purposes cured. This has happened in my experience in cases of lupus vulgaris associated with internal tuberculosis foci, and it is very familiar in cases of surgical tuberculosis. At one time we were inclined to attribute such occurrences to a specific action of the ol. morrhuae. Gradually the opinion gained ground that the oil was only of nutritive value. A paper such as Rose's, however, rather inclines one to think that there may be more in hydnocarpus in leprosy than there was in cod liver oil in tuberculosis, and this is emphasised by his results from continuing treatment for a number of years.

Unfortunately, in our experience so far as Moor House is concerned, the majority of the cases, in spite of all the treatment they have had, have either died or remained, in his terminology, "worse or unchanged." Only one case (Bishop) should be regarded as quiescent but not recovered, and another (Ventham) whom we have not seen for some years, who as far as I know may be regarded as quiescent and possibly recovered.

In view of these facts, it is impossible for me to do more than congratulate Dr. Rose on his results among the natives of British Guiana, and pray that a time may come when we can be as hopeful with regard to the treatment of the cases here.

\section{From Dr. E. Muir, Director of the Leprosy Research Department of the School of Tropical Medicine, Calcutta :-}

Dr. Rose's paper, "The Curability of Leprosy," is of great interest to all who are engaged in anti-leprosy work.

(1) The geographical area involved has the advantage of being a limited one with a population of only 310,000 . Only 801 cases of leprosy have come under observation, but no mention is made as to whether patients have been followed up to their homes and contacts examined. If this has not been done possibly such a survey, would lead to the detection of more cases.

(2) The table of results in early cases corresponds to the results that we obtain in India in places where the patients attend regularly and are efficiently treated.

(3) The results in advanced cases also correspond closely with results obtained in India under favourable circumstances.

(4) I thoroughly agree with Dr. Rose in his plan of keeping patients under treatment for six years after the disease has become " arrested" in the Manila Conference sense of the word. Routine examination only applies to examination of the skin and nasal mucosa. There is no doubt that, at least in patients who have been $\mathrm{C} 2$ or C3 cases, large numbers of bacilli may remain latent in the peripheral nerves without causing noticeable clinical signs. From the point of view of infecting others, these patients may not be immediately dangerous ; but any lowering of general health is apt to be followed by a relapse. In such cases, as Hayashi has pointed out, the leprolin test may continue negative or is only weakly positive. If the leprolin test from being weak or negative becomes moderately or strongly positive, this may be taken as a sign that infection has become almost or entirely eliminated from the body and that relapse is extremely unlikely to occur.

(5) "Cases treated in early childhood yield more readily to treatment than the adult." This is true if the treatment be begun early enough. What is far more important and likely to be effective than the treatment 
of very young children is their isolation from infectious adults, this being begun, if possible, from birth. So far the chief stress has, I think rightly, been laid on treatment. Treatment is very important, but the isolation of children from infectious cases is far more important; more and more the chief emphasis must be laid on this aspect of the question.

\section{From Dr. T. B. Welch, Special Leprosy Officer of the British Empire Leprosy Relief Association in Zanzibar :-}

Those concerned in the treatment of patients suffering from established leprosy will assuredly have welcomed Dr. Rose's interesting and important paper on "The Curability of Leprosy." Those, more particularly who, while fully recognising the limitations of oil of hydnocarpus and of its derivatives, retain their confidence in the value of these substances, will have found in that communication, at a time when that value is so extensively questioned, much to support their favourable opinion.

Oil of hydnocarpus and its derivatives are at present passing through the various phases through which they have been preceded by so many substances whose value has been first over-estimated and then unduly decried, but which have ultimately found their very real application in medicine. Perhaps the words "over estimated" do not here quite accurately describe the position; with greater exactitude it may be held that some of the earlier advocates of the use of these substances did not consider it necessary to stress the no lesser importance of the general management of the patient which, it is reasonable to suppose, they expected would assuredly receive the attention in leprosy in particular, the need for which is axiomatic in medicine in general; nevertheless, the primary importance of the general management has been emphasized over and over again. However, I have met not a few who have obviously been under the impression that these substances have been held out as being in some sense specifics which need only to be administered to the patient, irrespective of his general condition, for long enough for " cure " to follow; at any rate, where I have observed these substances most conspicuously to fail I have also seen inadequate attention being given to general management and to all that that implies, and this has appeared to be the prime cause of failure.

To emphasise the value of these substances, when associated with close attention to general management, I would here contrast their application in two institutions, of widely divergent types, whose activities I have had full opportunities of observing. In the first one, an asylum conducted on lines now long out of date, conditions were such as to render success inconceivable. Chronic intercurrent or concurrent disease, if obvious, received scanty consideration, while, if such condition was not obvious, its possible presence was ignored. Little was done to stimulate the inmates to take the exercise upon which their welfare so much depends. The dietary was markedly ill-balanced. Under such circumstances the inmates could not be restored to, and maintained in, a condition bringing the success of anti-leprotic measures within the bounds of possibility. However, such measures were attempted with little appreciation of their proper application, and with little discrimination in the judicious selection of patients. The results were entirely unsatisfactory and served only to create a profound scepticism regarding modern methods of treatment, though, obviously, these methods were not being applied. In the course 
of many months I saw no instance of convincing progress towards arrest attributable to the treatment given.

The second institution was a settlement conducted on more progressive lines, and here a fair increase of success was gained in the treatment of well-established leprosy. Close attention was given to the restoration of patients to as satisfactory a general condition as was attainable. Considerable facilities for the detection and treatment of intercurrent and of concurrent diseases were available and were freely used, while very real efforts were made to gauge the results of treatment clinically and in the laboratory. The importance of exercise was stressed, and it was possible to provide many of the more promising patients with work for which they were paid. The food was of very good quality, though the dietaries were less well balanced than might have been desired. Under such circumstances it was possible to bring a very considerable number of patients to such a condition that a good deal might reasonably be expected of more particularly anti-leprotic measures based upon oil of hydnocarpus and its derivatives. "These expectations were very fairly fulfilled. Anti-leprotic treatment of adults was voluntary ; in course of time it became increasingly appreciated. There were those, however, who were thought favourable subjects, but who consistently refused antileprotic treatment, and they served to some extent as controls.

Under systematic treatment, arrest was obtained in a fair number of cases even though their leprosy had, for the most part, manifested itself for several years. Patients were discharged only after repeated and consistently negative examination of smears, etc., made at moderately long intervals; relapses after discharge were few, so far as is known, but unfortunately there was no effective follow-up system of those discharged, though a good many discharges were under casual observation. Some of the patients who had had general treatment only appeared to be approaching the stage of arrest with deformity, though the advantage undoubtedly rested with the more completely treated.

One group of patients proved consistently poorly responsive to antileprotic measures ; this consisted of children of either sex, aged 10-14 years, in whom leprosy was well-established. All these children had histories of symptoms of several years' duration, and the poor results of treatment were such as might have been anticipated since the early appearance of widespread lesions would seem to indicate particularly low resistance.

The conclusions to be drawn from the observations made under the conditions that have been detailed would seem to be :-(1) That oil of hydnocarpus and its derivatives have an important place in the adequate treatment of those suffering from leprosy, which is, however, limited by the need for patients being in or being brought to good general condition. (2) That these preparations are of little value in children who have shown well marked symptoms at an early age, e.g., in the second five year period, which have persisted into the third five year period of life.

Finally, I would stress the importance of careful discrimination in the selection of patients with these substances; clinical observation, aided by procedures such as, more particularly, the erythroazte sedimentation test enables such selection to be made with a fair degree of certainty. Endless pessimism is produced among the patients and much disbelief among medical men and among the public generally by numerous failures following the promiscuous application of forms of treatment, however valuable within their limits. Few steps would do so much to commend their use, as would their restriction to those believed likely to benefit 
thereby, as against their extension to those who, it is hoped rather than expected, might conceivably respond.

I do not wish to seem to assert that, where oil of hydnocarpus and its derivations have failed, there has necessarily been failure in general treatment or in the sclection of patients. I have merely tried plainly to outline my experiences in the hope that by so doing I may contribute a little to that full discussion of the value of these substances and of their limitations in the treatment of those suffering from leprosy that is now so desirable. 